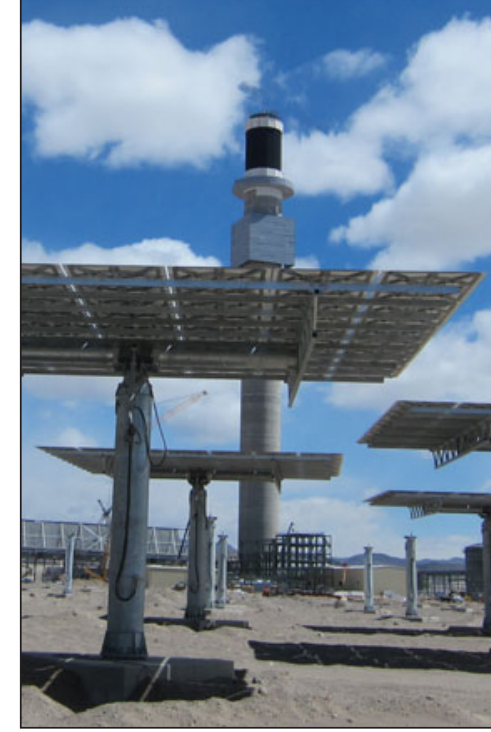

\title{
Research on metal hydrides revived for next-generation solutions to renewable energy storage
}

By Melissae Fellet

Feature Editors Craig E. Buckley, Mark Paskevicius, and Drew A. Sheppard
Sheat ome renewable energy power plants store solar energy as heat, which is used to generate electricity after sunset. But as with many clean energy technologies, economics influences how far energy storage can spread through the emerging market for commercial-scale solar power. A class of materials called metal hydrides could be the next generation of heat storage materials to help reduce the cost of thermal energy storage at solar power plants, and thus further the development of renewable energy worldwide.

The most efficient use of sunlight to generate enough power for base-load consumption is called concentrating solar power (CSP). At CSP plants, mirrors focus sunlight onto a fluid, like oil or molten salts. The hot fluid then flows through a heat exchanger, producing steam to drive a turbine that generates electricity.

There are 80 operational CSP plants around the world, mainly in Spain and the United States, with $1.9 \mathrm{GW}$ of total capacity as of March 2012. Another 23 are under construction in India, China, Australia, and South Africa, among other places. Currently $40 \%$ of the commercial CSP plants store thermal energy to generate from 30 minutes to 15 hours of electricity on demand.

One CSP plant with thermal storage is a state-of-the-art 110 MW plant in Nevada called the Crescent Dunes Solar Energy Plant, with construction to be finished by the end of 2013. At this plant, energy storage is integrated into the plant's power generation system, and electricity production can occur without intermittency. "Depending on what a utility company needs, we can develop this plant to run 24 hours a day, seven days a week," said Mary Grikas, Vice President of Communications at SolarReserve, the company developing the Crescent Dunes plant. "That makes this plant more like a coal or natural gas plant, as far as a utility company is concerned."

At this plant, solar energy is collected and stored in a material called molten salt, a mixture of sodium nitrate and potassium nitrate, both ingredients commonly found in fertilizer. During the day, mirrors shine sunlight onto a receiver atop a central tower. Molten salt flows through the tower, where it is warmed to $565^{\circ} \mathrm{C}$ as it flows through the receiver. The hot salt is then pumped into an insulated storage tank. When electricity is needed during the day or night, the hot salt is moved from the tank through a heat exchanger, where it cools to about $290^{\circ} \mathrm{C}$ as the stored heat generates steam to power a standard turbine. The cooled salt then travels to a second storage tank until being pumped into the receiver again.

The 10-hour heat storage capability at the Crescent Dunes plant requires about 32,000 metric tons of molten salts. That large amount of salt can increase costs to build CSP plants with storage. Using a storage material with a higher energy density than molten salt could help reduce some of the storage costs in a CSP project because less material would be required to store the same amount of energy.

A well-researched class of materials called metal hydrides appears poised to be the next generation of storage at concentrated solar power plants. Made from inexpensive, readily available materials such as magnesium, calcium, and titanium, these materials are 10 to 30 times more energy dense than molten salt (see Table), though some of that theoretical thermal storage capacity will be lost when engineering a storage system. Solar thermal storage using metal hydrides requires a smaller storage tank and less storage material than a system with molten salts, said Ewa Rönnebro, a senior research scientist at Pacific Northwest National Laboratory where she is leading a project on developing a thermal energy storage technology utilizing metal hydrides for high-temperature power generation. "Comparing the technical solutions, it's possible to see that metal hydrides will be cheaper than molten salt," she said.

Metal hydrides like titanium-iron hydride were first explored during the oil crisis of the 1970s as materials to store hydrogen for cars and to increase the energy density of batteries. These materials reversibly absorb and desorb hydrogen gas from their crystalline matrix. Energy is stored in the chemical bonds that change as a metal hydride releases hydrogen gas to become just a metal. That energy is released as heat when the metal absorbs hydrogen and reforms the metal hydride.

Magnesium hydride, another material first explored as a result of the oil crisis 40 years ago, is commonly studied for thermal energy storage because of its high hydrogen storage capacity: $7.7 \mathrm{wt} \%$. The material reversibly absorbs hydrogen gas at around $400^{\circ} \mathrm{C}$, the optimal temperature for many solar thermal plants 
operating today, but too low to take advantage of the high temperatures achievable at plants like Crescent Dunes.

But the amount and pressure of hydrogen gas released by this material must be considered when building a thermal storage system with it. At $400^{\circ} \mathrm{C}$, magnesium hydride creates a hydrogen gas pressure of $20 \mathrm{Atm}$ at equilibrium. The volume of gas to be stored, however, could be contained in known storage systems such as gas tanks or natural salt caves, said Michael Felderhoff of the Max-Planck-Institut für Kohlenforschung, where these materials have been researched since the 1980s.

The composition of the metal hydride influences the temperature and pressure at which the hydrogen absorption and desorption is reversible, with high-temperature, low-pressure materials favored for CSP storage. Higher operating temperatures improve the efficiency of the turbine that generates electricity, and lower pressures simplify the equipment needed for storage. Targets from the US Department of Energy to make solar energy costcompetitive with other forms of unsubsidized energy aim to have heat storage for CSP plants at $600^{\circ} \mathrm{C}$ or greater. Molten salts break down at these temperatures, but some metal hydrides meet the target. Sodium magnesium hydride, titanium hydride, calcium hydride, and lithium hydride reach operating temperatures between $600^{\circ} \mathrm{C}$ and $1000^{\circ} \mathrm{C}$.

A common design strategy for thermal storage systems pairs such "high-temperature" metal hydrides with another metal hydride that acts as gas storage. This second "low-temperature" hydride, like sodium aluminium hydride, absorbs hydrogen released by the primary "high-temperature" hydride during the day. At night, it delivers hydrogen to the primary hydride, which absorbs the gas and releases the stored heat (see Figure).

Proper pairing of the high- and low-temperature hydrides maximizes this system's efficiency. Ideally, the low-temperature hydride releases hydrogen gas at a pressure similar to the operating pressure of the high-temperature hydride. That allows hydrogen gas to flow consistently between the two hydrides and provide constant heat release.

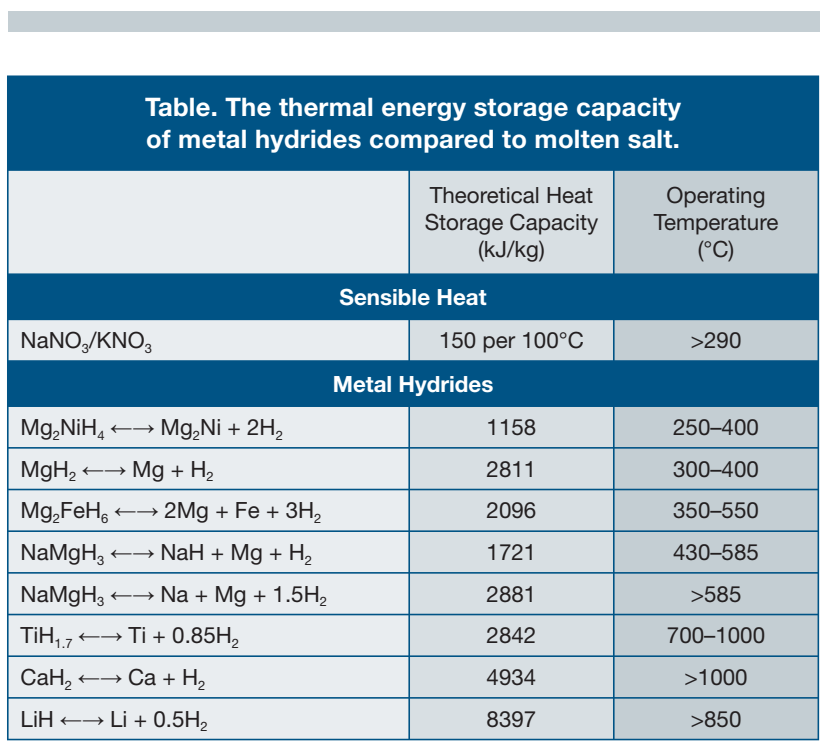

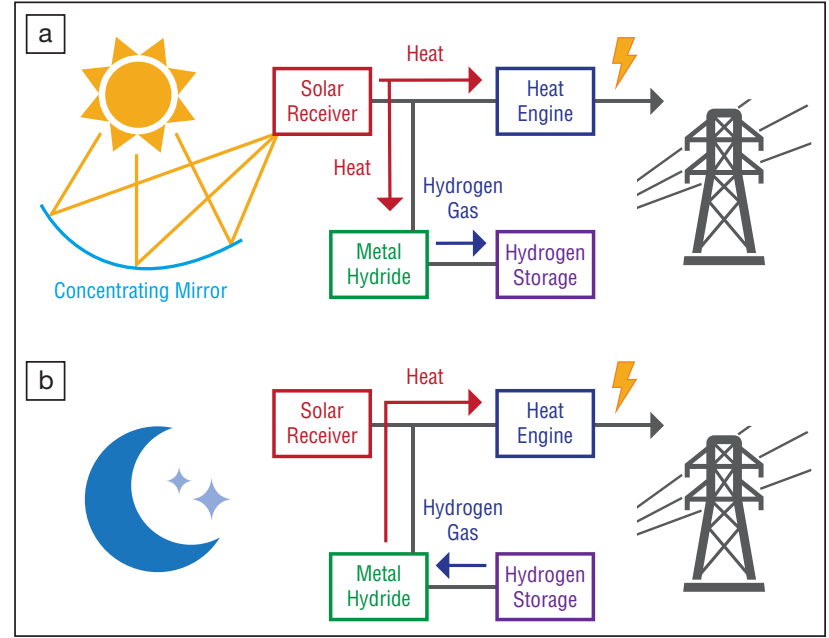

A schematic of the concentrating solar thermal system coupled with metal hydrides as a thermal storage medium during (a) daytime and (b) nighttime operation.

Basic research is under way at Savannah River National Laboratory in the United States, in collaboration with a laboratory at Curtin University in Australia, and also at Pacific Northwest National Laboratory, to identify high- and low-temperature hydrides with operating temperatures and pressures that provide an efficient paired system. Some of that work identifies hydrides with higher operating temperatures, to complement previously discovered materials that release hydrogen below $200^{\circ} \mathrm{C}$, materials that are potentially useful today as low-temperature hydrides.

Another challenge in identifying metal hydrides appropriate for solar thermal storage involves confirming the material can store heat for at least a 30-year lifetime of the CSP plant. That means a metal hydride has to withstand around 11,000 cycles of hydrogen absorption and desorption without losing a significant amount of its ability to bind hydrogen.

Once a metal hydride has been identified as a storage material, it is important to optimize the thermal conductivity of the material so that heat enters and leaves the material as quickly as possible, said Gavin Walker, a materials scientist at the University of Nottingham who is engineering a magnesium hydride system with funding from the energy company E.ON. One way to do that is to add an affordable heat transfer material, like graphite, to the metal hydride. The structure of the storage tanks can also be changed to improve the conductivity by adding fins that help with heat transfer, for example.

Current estimated costs for metal hydride heat storage systems are similar to that for molten salt systems, but further research will likely find hydrides, especially high-temperature ones, that are cheaper than molten salts, said Craig Buckley of Curtin University. Installation costs could be reduced further if a costeffective pressurized hydrogen storage tank replaces the lower temperature hydride, he said.

Several laboratories around the world are currently working to build bench-scale, or larger, prototypes of various metal hydride thermal storage systems. Continued funding can further the materials science and engineering efforts to enable scale-up for commercialization. 